\title{
Teaching Chimps to be Chimps
}

\author{
Michae/ Brambell
}

I cannot claim to be dispassionate or unbiased about Stella Brewer's lovely book The Forest Dwellers.* I played a part, albeit a small one, in the tale it has to tell. It is the story of Stella Brewer's life from the age of seventeen until her middle twenties; of the lives of several chimpanzees from early childhood until young adulthood; of one orphan chimpanzee that Stella found in pitiful circumstances in the Banjul market in the Gambia and resolved to save, and of how it comes to be not so much life itself that must be saved but the chance for the chimpanzees to live their lives to the full in the wild. Several of the animals die or get lost in the course of the book, but there is no feeling of failure in this story of a very brave and, in the end, successful attempt to do something useful in man's relations with this close relative. It is gently written, but the story is full of bite, with plenty of amusing incident.

Having become the guardian of a handful of confiscated chimpanzees Stella soon realised that she could not keep them for ever. But never having learned to live on their own, they would have to be taught, and the only way was to teach them herself. Again and again the simplicity of the lessons comes over: how to find food, where to make nests, what to be frightened of, and always Stella learning to do what the chimpanzees would expect from older chimpanzees, until at last they were able to live independently of her and even to breed.

Two of the chimpanzees Stella reintroduced to the wild were born in London Zoo and, having been abandoned by their mothers, had to be reared in my own house. What worse start could Cameron and Yula have had to prepare them for a life in the wild? Cameron, abandoned within a few hours of birth, was found clinging frantically to the shin of an 'aunt' who did not want him, nor know what to do with him. Yula had had to be taken from her mother at three months because she was not being properly fed.

For the first six months of Cameron's life we had the joy, and he the disaster, of rearing him in our home. He had to travel in a carry-cot and our children had to put up with the disruption. It was great fun for us. My late father carried Cameron's photographs with him and would produce it as 'my fifth grandchild' until an irreverent young lady commented on the family likeness. But to Cameron, as to any animal that has to be hand-reared, it was a disaster. Young chimpanzees need to grow up with other chimpanzees. In the wild Cameron would have been dead; in the zoo he was still alive, but we did not know how to reintegrate him into the robust social group of chimpanzees.

From the start we had tried to keep him as chimpanzee-orientated as we could. He was taken to see the other chimpanzees in the zoo, and at three months to 'play-school' in the old monkey house, where he was surrounded by the noise, smells and sights of other apes. At six months, when he was no longer dependent on us, he went back to live with other younger chimpanzees, though we dared not put him in with adults. By this time Yula had joined him and they grew up together.

At about this time zoos were beginning to claim their role as reservoirs of endangered stock until the problem of mankind's overpopulation had been

* Collins, $£ 5.75$. 
solved and land could again become available for uncontrolled natural growth. The snag was that we did not know if the animals in the reservoir could be channelled to where they were wanted. Could advanced animals like chimpanzees be put back into the wild? Stella Brewer knew of a stretch of forest which seemed to be unthreatened, which held fewer chimpanzees than before so that there was probably room for more, and in the corner of Africa from which Cameron's and Yula's ancestors had come. Money was found, and Cameron and Yula flew out to join the wild-born chimpanzees Stella had already started to train for reintroduction into the wild. It was a cliffhanger. Cameron was not at all sure he wanted to be dominated by the sub-adult William, the local boss chimpanzee in Stella's camp. He did not know the same language of gestures and response, nor understand why Yula got on well with William. There came the time when they could no longer be kept penned up, and Stella had to commit everything to the hope that once all the chimpanzees were in the open in the camp Cameron and Yula would stay. They could have walked out of camp and gone on walking, but they did not. They stayed to learn how to get on in the wild. Some time later Cameron left camp of his own accord, but Yula is still there. Cameron has not been back, but Stella is convinced that on four occasions he came close. It could well happen that he will come back and forth as the females become adult, for that is the way of male chimpanzees.

The project has been worthwhile. We now know it can be done. When the felling times and killing times are over we will need healthy chimpanzees like Cameron and Yula to restock the wild. We will also need fruitful forests like that in the Senegal, and we will need people like Stella Brewer prepared to see it through and with the guts to stand up to the discomforts and dangers, not least the tantrums of maturing male chimpanzees. We will need people with the charm and persuasiveness to get the necessary backing. It would be great if they could also find Hugo van Lawicks to make films like 'Return to Mount Assirick', but it would be asking altogether too much to expect them to write books as good as 'The Forest Dwellers'.

Dr Brambell is Curator of Mammals in the London Zoo, a member of FPS Council, and Chairman of the Scientific Authority for Animals to advise on the Convention on International Trade in Endangered Species (CITES).

\section{Parma Wallaby in Australia}

Thirteen years ago the parma or white-throated wallaby Macropus parma was thought to be extinct, but in 1965 a small population was discovered on the small island of Kawau in New Zealand where they had been introduced about 1870 . New Zealand has no native wallabies and they are classed as 'noxious animals' and shot on sight. Great efforts were made to protect this population (including official protection), and many zoos round the world established breeding groups, as described in Oryx, May 1971. Then in 1972 parma wallabies were rediscovered in Australia, in the Great Dividing Range of coastal New South Wales, where there appears to be a thriving population. In an account of this discovery in Australian Wildlife Research, 4, 2, G. M. Maynes recommends that because the wallaby's range is so reduced, colonies localised and density low, it should be regarded as a 'rare species' even though it may be locally common. Its favoured habitat appears to be wet sclerophyll forest with a thick shrubby understorey and grass areas nearby. It was the parma wallaby of which a politician declared that 'it must never be allowed to become extinct again'. 